\title{
The Effect Level of Expertise on the Didactic Functionalities for the Teaching Gestuality of Athletic Activities: The Shot Put
}

\author{
Houda Dammak ${ }^{1,2}{ }^{*}$, Liwa Masmoudi², Salma Abedelmalek ${ }^{3}$, Khouloud Aloui ${ }^{1}$, Nizar Souissi $^{2}$ \\ ${ }^{1}$ Research Laboratory "Sports Performance Optimization”, National Center of Medicine and Science in Sports (CNMSS), Tunis, Tunisia \\ ${ }^{2}$ High Institute of Sport and Physical Education KsarSaiid, University of Manouba, Tunis, Tunisia \\ ${ }^{3}$ Department of Physiology and Functional Explorations, Sousse Faculty of Medicine, Sousse, Tunisia \\ Email: ^houdadammakghorbel@hotmail.com
}

How to cite this paper: Dammak, H., Masmoudi, L., Abedelmalek, S., Aloui, K. and Souissi, N. (2016) The Effect Level of Expertise on the Didactic Functionalities for the Teaching Gestuality of Athletic Activities: The Shot Put. Open Access Library Journal, 3: e3052.

http://dx.doi.org/10.4236/oalib.1103052

Received: September 29, 2016

Accepted: November 13, 2016

Published: November 16, 2016

Copyright $\odot 2016$ by authors and Open Access Library Inc.

This work is licensed under the Creative Commons Attribution International

License (CC BY 4.0).

http://creativecommons.org/licenses/by/4.0/

\section{(c) (i) Open Access}

\begin{abstract}
The aim of this study is to investigate the effect of expertise on didactic functionality of the teaching gesture of two teachers with different expertise and similar experience. The audio-visual method was used with interviews. Our results showed that the teaching gestures in the teaching of shot put depend on the teacher's expertise (chi-square $=18.252 ; \mathrm{p}=0.01$ ). Indeed, the expert teacher uses more representational gestures in comparison with the polyvalent that uses the manipulations in favour of other actions. Regarding learning structures used (chi-2 $=22.56 ; \mathrm{p}=0.001)$, both teachers define first, then they regulate, then they evolve and finally they institutionalize. Moreover, the mobilized didactic technique by both teachers is topogenesis (chi-square $=31.822 ; \mathrm{p}=0.001$ ). In conclusion, the teaching gestures in the teaching of shot put depend on the teacher's expertise. However, more work experience widens; the differences are related to the expertise decrease.
\end{abstract}

\section{Subject Areas}

Education

\section{Keywords}

Teacher Gestures, Expertise, Didactic Functionality, Shot Put

\section{Introduction}

It is well established that motility has a potent role especially on physical education whose gesture presents a fundamental position in the didactic interactions [1]. Accord- 
ing to [2] and [3], non-verbal communication accounts for over $50 \%$ of the transmitted messages. That is why communicative gestures of the teacher are in a privileged position in the process of teaching and especially in the transmission of knowledge.

Previous studies showed that verbal statements are accompanied by many gestures [3]-[8]. Thus, the gesture is a very functional way of intervention of the teacher of sport and physical education in order for the knowledge transfer taking place optimally. On the other hand, the professional experience and expertise are central in didactic interactions. Several studies showed that knowledge of teaching content in EPS is essentially contextualized knowledge related to the professional experience and the importance of their use in situations of apprenticeship [9] [10] [11] and [12]. Other research in educational sciences has pointed inter-individual variability between expert teachers and less experts. In this context, [13] showed that the expert teacher is easier in his gestures and clear in its definitions.

According to the literature, the expertise and the teaching gestures were studied in several APS as boxing [14], gymnastics [8] [15], judo [16], swimming [4]; however no study was interested in studying the effect of expertise on the actions of athletics activities particularly the shot put.

Hence our present research is a comparative study of the teaching gesture of two teachers of similar experience and different expertise. Thus the aim of this study was to make a specific gestural repertoire for each teacher's expertise, and deduct the differences and similarities of the categories of actions and their functionality in both didactic teachers.

\section{Methodology}

\subsection{Characteristics of the Observed Participants}

We have selected two different profiles of teachers. They are a teacher in the same public secondary school in Sfax. Both teachers have more than twenty years of experience, both have had the same university track and graduated from "sciences and technology of physical activities and sports", one specialist in athletics and the second is a gymnastics specialist (SANA and SARA).

"SANA" is the pseudonym chosen to keep the confidentiality of "athletic expert". She had practiced athletic for twelve years, including seven years a member of the Tunisian national athletics team (specialty shot put). She had a federal diploma of second degree coach.

"SARA" is the pseudonym chosen to keep the confidentiality of "gymnastic expert". She had practiced gymnastic for twelve years. She had a federal diploma of second degree coach. The observations took place in two senior classes that belong to two different specialties.

Students observed in this study are the same skill levels.

\subsection{Experimental Design}

Data collection allows setting up different corpuses [17]. We have used audio-visual 
recording and we have recorded different interviews with the two teachers.

\subsubsection{Audio-Visual Recording}

To investigate the effect level of expertise on gestural functionality, we used the methodology of observations [18]. Two calibrated cameras were presented: one placed at wide angle, allowed to film the entire Wide field. And the second was teacher-centered, followed all his movements. Concerning the video-recorded and observed class sessions, we have taken note of the session planning done by the two teachers in order to know the items taught. We have also taken some notes so as to have a better idea about the tasks proposed to the students, about teacher's action in work presentation, and also in her guidelines during the action [17]. We have also taken note of students' motor action and their progress over the class session [19]. Likewise, all interviews with both teachers were recorded using a Dictaphone (Figure 1).

\subsubsection{Interviews}

Each interview was conducted in a room where there was the teacher and researcher. These interviews are intended to update projects and assessments of teachers in the minutes before or after the observation. They consisted of the teacher let speak from a question that the target object of inquiry. These interviews allow one hand, access to experiential knowledge from the teacher through the ant-cycle, and his teaching activity through interviews, pre and post session according to [20].

\subsection{Data Transcription and Condensation}

Concerning the qualitative analysis principles [21], the first step consists in copying down the data collected during the interviews (pre and post class session and pre and

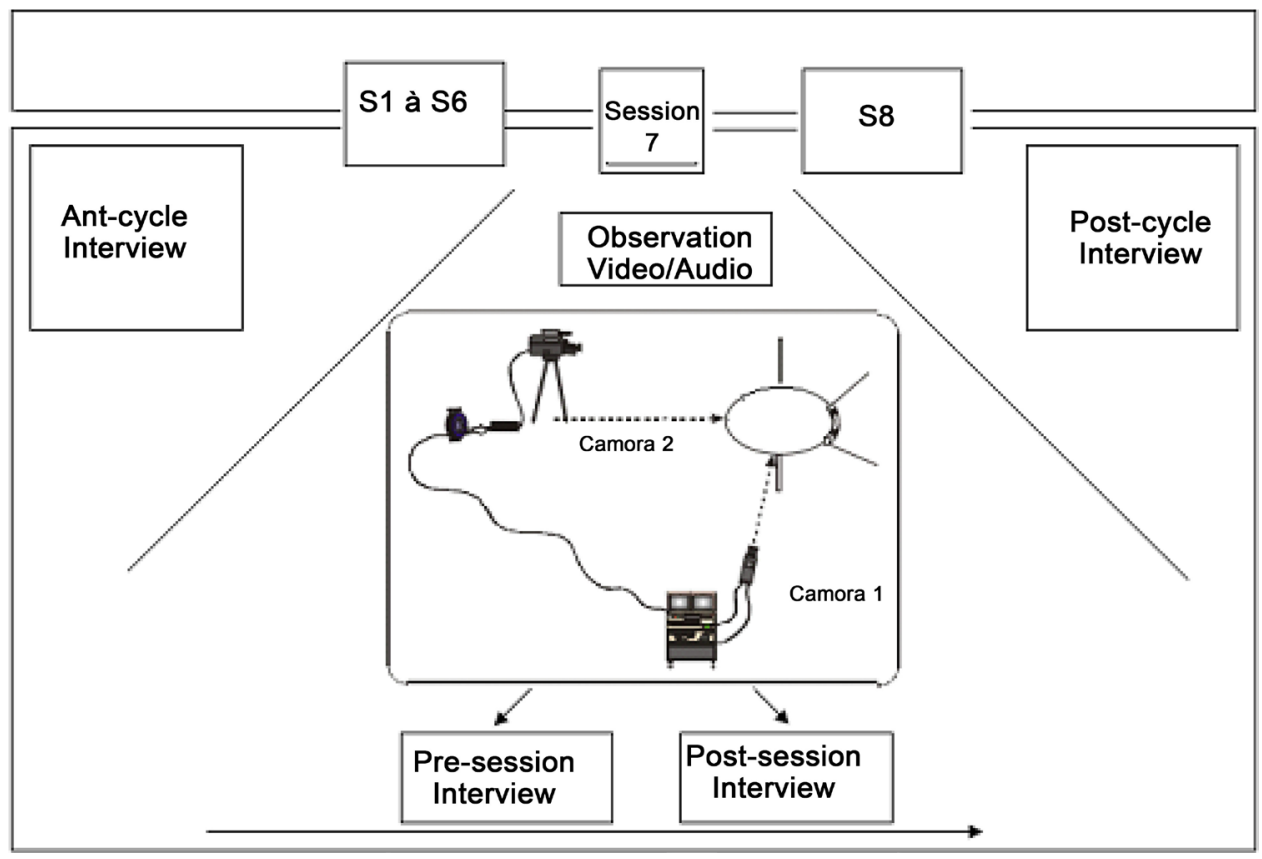

Figure 1. Pattern of data collection (Schubauer-Leoni \& Leutenegger, 2002). 
Table 1. Categories of coding for each observed gestural unit (Kamoun and Amade Escot, 2007).

\begin{tabular}{clc}
\hline Gestural categories & \multicolumn{2}{c}{ Didactic functionality } \\
\hline - Spatial index gestures & Definite & Topogenesis \\
- Illustrative and substitutionnal gestures & Devolve & Mesogenesis \\
- Representational gestures & Regulate & Chronogenesis \\
- Manipulations gestures & Institutionalize & \\
- Symbolic gestures & & \\
\hline
\end{tabular}

post cycle). It consists in producing the observation data of the different class sessions in simplified forms of analysis. We have summarized the video recorded data of each class in a synopsis [17]. Concerning the classification of gestural categories, we will categorize gestural units used by both teachers. To this, since our study focuses on the comparison of two teachers with similar experiences and different expertise; we reproduce exactly the same method of data collection and processing of information [8] (Table 1).

- The spatial-index gestures: Spatiographics gestures that represent a spatial relationship which refers to an object and index gestures; Gestures of scores and designation [4].

- Illustrative and substitutional gestures: The teacher uses her body or any part of his body to demonstrate, reproduce or replace a hardware device or human.

- The representational gestures: The teacher uses part of his body to represent or evoke the action of another body part.

- The manipulations gestures: The task of the teacher to help a student to move or execute an action

- The symbolic gestures: The gestures able of providing communication without the use of a word [22].

\subsection{The Classification of a Modeling of Teachers}

The Didactic Model chosen in our study is described in first time by [23]; and [24] cover many levels of description, going from fundamental structures of teacher action (defining, regulating, devolving, institutionalizing) borrowed from [25] theory of didactic situations, to descriptors of joint action borrowed from [26]: mesogenesis, topogenesis, and chronogenesis: Define: Identify and nominate the constituent objects of the situation during the lesson in order to optimize [27], devolve: The process by which the teacher ensures that students assume their responsibility in achieving the task [28], regulate: Refers to the teacher's interventions when students realized an activity and institutionalize: Refers to everything the teacher did for that knowledge, knowledge, teaching and learning issue, is legitimate in the class institution [28].

For technical teaching, we will refer to the model done by [24] and reproduced by [8]. Indeed, elements four structuring teacher's actions and which are at the basis of this didactic relationship: define, regulate evolve and institutionalized. This structure only makes sense if you consider that it supports a triple production: Production up the teacher and student (topogenesis: defines the evolution of the systems of the place of the teacher and students as regards the objects of knowledge), the teaching and learning 
time (chronogenesis: defines what is related to the production of knowledge in the course of didactic temporality) and production environments situations production and objects. Organization reports to these items (mesogenetic: defines the evolution of a complex system of objects). Thus, for each gesture coded to correspond to a structure and a technical learning. For each coded gesture match a structure and a technical teaching from the teacher [29] [30] [31].

\subsection{Didactic Analysis of Shot Put}

In our study, we are interested to study the effect of expertise on the actions of teachers in school. Therefore, our protocol requires the analysis of the translation technique in shot put (according to official instructions of Tunisia, 2012). Shot-putting requires great explosive strength, together with the ability to perform precisely timed movements in a conned space. The athlete's objective is to project the shot as far as possible, but competition regulations restrict the technique that may be used. The shot must be thrown from the shoulder using one hand and it must be held near to the chin throughout any preliminary movements. The most widely used throwing technique is the translation technique (Figure 2).

Session carried out by two teachers.

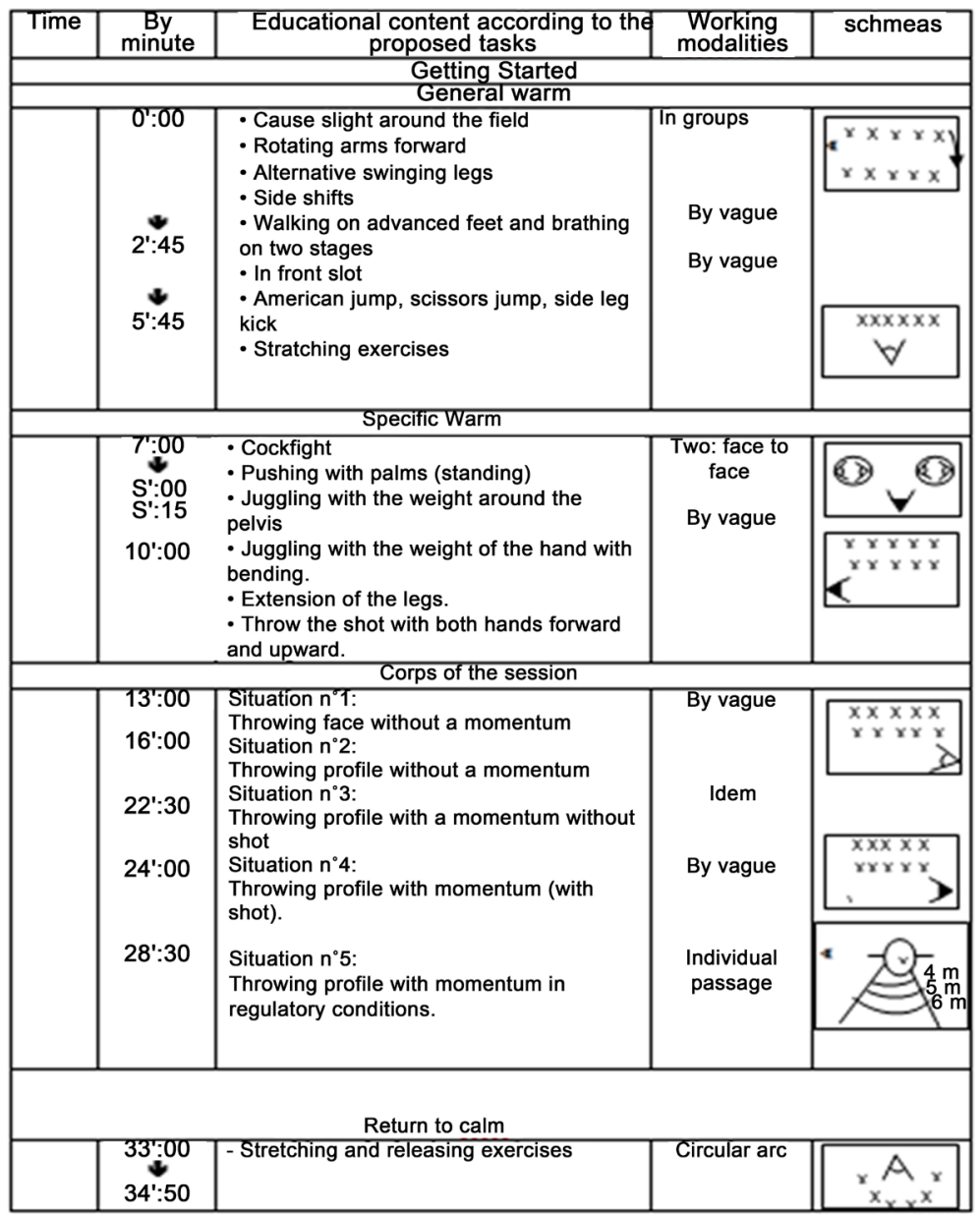



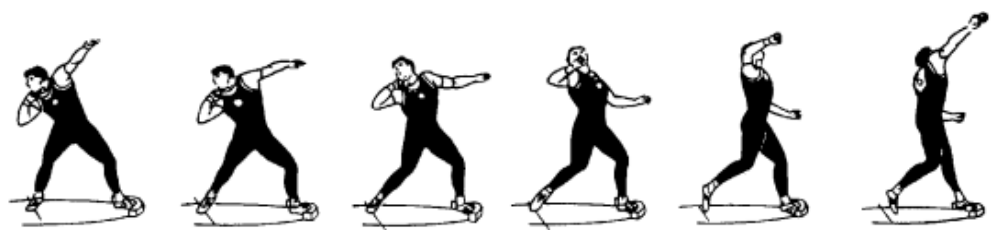

Figure 2. Sequence of movements by a shot-putter using the translation.

\subsection{Statistical Technique Analysis}

The statistical analysis was performed using Statistica (Stat Soft, France). Values are expressed as percentages. Data analysis was performed by the chi-square (X2). It is used to investigate whether distributions of categorical variables differ from one another. Basically categorical variable yield data in the categories and numerical variables yield data in numerical form. The level of statistical significance was set at $(\mathrm{p}<0.05)$.

\section{Results}

\subsection{Distribution of the Gestures of Two Teachers}

The distribution of the gestures observed for both the two teachers (expert and polyvalent) is presented in (Table 2). Our results showed a significant difference in the distribution of the gestures used by teachers (chi-square $=18.252 ; \mathrm{p}=0.01$ ). Indeed, the expert uses more gestural sequences in learning shot put in comparison with the polyvalent. Thus, for a total time of $71 \mathrm{~min}$ and $11 \mathrm{~s}, 570$ gestural sequences as follows: 336 for the expert during 36 minutes and 17 seconds. However, only 234 gestural were observed during 34 minutes and 54 seconds for the polyvalent.

\subsection{Distribution of Gestural Categories Depending on the Expertise of Teachers}

The analysis of variance showed a significant gestural categories effect (chi-square = 31.52; $\mathrm{p}=0.01$ ) between two teachers according to their level of expertise. Indeed, the gestures category of spatial-index is the most used for both teachers (expert and polyvalent) with 278 gestures for the expert and only 123 for the polyvalent (Table 3 ).

In general, we note the following findings:

- The substitutional and the illustrative are in the second place with $20.3 \%$ for the expert and $34.8 \%$ for the polyvalent.

- The representational are positioned in last place and represent $3.2 \%$ for the polyvalent and they are greater in the expert with 7.9\%.

- Concerning the manipulation, they are rarely in expert $2 \%$ and they present $6.5 \%$ for the polyvalent.

- The symbolic gestures present a percentage of $7 \%$ for the expert teacher, and $5.7 \%$ for the polyvalent.

\subsection{Classification Gestural Categories According to the Structures of the Educational Action}

The statistical analyses showed a significant difference in the distribution of didactic 
Table 2. Distribution of the gestures observed in expert and polyvalent teachers.

\begin{tabular}{ccccc}
\hline Teacher & $\begin{array}{c}\text { Time of } \\
\text { observation }\end{array}$ & $\begin{array}{c}\text { Number of unit } \\
\text { gestuality }\end{array}$ & $\begin{array}{c}\text { Number of } \\
\text { gestual } \\
\text { categories }\end{array}$ & $\begin{array}{c}\text { Number of gestual } \\
\text { categories/min }\end{array}$ \\
\hline Expert & $36^{\prime} 17^{\prime \prime}$ & 336 & 443 & 12.24 \\
Polyvalent & $34^{\prime} 54^{\prime \prime}$ & 234 & 247 & 7.15 \\
Total & $71^{\prime} 11^{\prime \prime}$ & 570 & 690 & 9.70 \\
\hline
\end{tabular}

Table 3. Distribution of gestural categories of teachers.

\begin{tabular}{cccccccc}
\hline \multicolumn{7}{c}{ GESTUAL CATEGORIES } \\
\hline & Spatial-index & $\begin{array}{c}\text { Illustrative and } \\
\text { substitute }\end{array}$ & Representational & Manipulations & Symbolic & Total \\
\hline \multirow{2}{*}{ Expert } & Number & 278 & 90 & 35 & 9 & 31 & 443 \\
& $\%$ & $62.80 \%$ & $20.30 \%$ & $7.90 \%$ & $2 \%$ & $7 \%$ & $100 \%$ \\
\hline \multirow{2}{*}{ Polyvalent } & Number & 123 & 86 & 8 & 16 & 14 & 247 \\
& $\%$ & $49.80 \%$ & $34.80 \%$ & $3.20 \%$ & $6.50 \%$ & $5.70 \%$ & $100 \%$ \\
\hline \multirow{2}{*}{ Total } & Number & 401 & 176 & 43 & 25 & 45 & 690 \\
& $\%$ & $58.10 \%$ & $25.50 \%$ & $6.20 \%$ & $3.60 \%$ & $6.50 \%$ & $100 \%$ \\
\hline
\end{tabular}

structures of the action used by both teachers (chi-square $=21.112 ; \mathrm{p}=0.001$ ). Likewise, the primary function of the teaching gesture is defining the didactic environment independently of the level of expertise with $64 \%$ for the expert and $82.1 \%$ for the polyvalent. Regarding the regulatory function, the highest percentage is observed on the expert with $30.4 \%$ in comparison with $15.7 \%$ for the polyvalent. On However, the devolution function has only $1.7 \%$ in polyvalent teacher in comparison with $4.8 \%$ for the expert. Furthermore, the function of institutionalization keeps the same rank for both teachers independently of the level of expertise $(0.6 \%$ to $0.4 \%$ for expert and polyvalent respectively).

Regarding the cross between gestural categories and didactic structures (Table 4), the chi-square showed no significant differences was observed (chi-2 $=22.56 ; \mathrm{p}=0.001$ ), except at the level crossing structures with spatial-index movements.

Indeed, our results showed that:

- To define the category "spatial-index" is the most used in both teachers' relatively high percentages $74 \%$ for the expert and $59 \%$ for the polyvalent.

- To devolve, expert appeals to symbolic gestures, with a percentage of $50 \%$ and representational gestures with a percentage at $31.3 \%$. The polyvalent uses only symbolic gestures to devolve with $66.7 \%$.

- To regulate, expert teacher use spatial-index gestures with $52.1 \%$, while the polyvalent uses illustrative gestures with a percentage of $48.6 \%$.

- Finally, to institutionalize the expert uses symbolic gestures with $71.4 \%$ and the polyvalent uses the spatial-index with a percentage of $100 \%$. 


\subsection{Classification Gestural Categories Based Didactic Techniques Used by Teachers}

The chi-square test shows a significant difference (chi-square $=31.822 ; \mathrm{p}=0.001$ ) in the use of didactic technical in both two teachers (Table 5). Indeed, both two teachers used the topogenesis technique in the first with $43.5 \%$ for the expert and $53 \%$ for the polyvalent. Similarly, the expert teacher uses more mesogenic technique with $21.72 \%$ and only $4.7 \%$ for the polyvalent. Regarding the chronogenesis gesture appear to be classified in second place independently of the expertise of the teacher with a high percentage observed for the polyvalent $42.3 \%$ and $34.8 \%$ for the expert.

\section{Discussion}

The aim of this study was to investigate the effect of expertise on didactic gesture functionality in the teaching of the shot put. Our results showed similarities and differences in the distribution of the teachers' gesturing for the expert and polyvalent.

Concerning categories spatial-index gestures are the most frequently used by both teachers. The spatial-index gesture of shot put are often indicated the locations (i.e., the tempo or time to start and stop the action, to designate an object, to clarify the meaning and direction, height or distance, speed ....).

Furthermore, we observed that the expert "SANA" uses on average (12 categories gestural/min) during the observed session, while the polyvalent teacher "SARA" uses (7

Table 4. Frequency distribution of gestural units according to their educational structures.

\begin{tabular}{|c|c|c|c|c|c|c|}
\hline \multicolumn{7}{|c|}{ Structure of didactic action } \\
\hline & & Definition & Regulation & Devolution & Institutionalization & Total \\
\hline \multirow{2}{*}{ Expert } & Number & 216 & 102 & 16 & 2 & 336 \\
\hline & $\%$ & $64.30 \%$ & $30.40 \%$ & $4.80 \%$ & $0,6 \%$ & $100 \%$ \\
\hline \multirow{2}{*}{ Polyvalent } & Number & 188 & 36 & 4 & 1 & 229 \\
\hline & $\%$ & $82.10 \%$ & $15.70 \%$ & $1.70 \%$ & $0.40 \%$ & $100 \%$ \\
\hline \multirow{2}{*}{ Total } & Number & 404 & 138 & 20 & 3 & 565 \\
\hline & $\%$ & $71.50 \%$ & $24.40 \%$ & $3.50 \%$ & $0.50 \%$ & $100 \%$ \\
\hline
\end{tabular}

Table 5. The use of gestuality and teaching techniques according to the level of expertise.

\begin{tabular}{cccccc}
\hline \multirow{5}{*}{ Expert } & \multicolumn{5}{c}{ Didactic technical } \\
\hline \multirow{2}{*}{ Polyvalent } & Number & 117 & Topogenesis & Mesogenesis & Total \\
& $\%$ & $34.80 \%$ & 146 & 73 & 336 \\
& Number & 99 & $43.50 \%$ & $21.70 \%$ & $100 \%$ \\
\hline \multirow{2}{*}{ Total } & $\%$ & $42.30 \%$ & 124 & 11 & 234 \\
& Number & 216 & $53.00 \%$ & $4.70 \%$ & $100 \%$ \\
\hline & $\%$ & $37.90 \%$ & $47.40 \%$ & 84 & 570 \\
& & & & $14.70 \%$ & $100 \%$ \\
\hline
\end{tabular}


categories/min). Thus the teacher "SARA" uses less gesture based on a verbal language to convey the knowledge skilled. This could be explained by the effect of expertise in EPS. These results are in accordance with those observed by [14] who indicate the crucial role of expertise in the teaching of physical activity.

Our results showed that gestures "spatial-index" ranked first. These results confirm those of [8] who found that the "spatial-index" gestures are the most used by the teachers independently of the expertise level.

In this context, [6] called their "intention" to designate, to indicate (category special-index gestures), present, reproduce or substitute (category illustrative gestures and substitutional) to raise (representational gesture category), manipulate and finally to symbolize (category of symbolic gestures). These actions are to prevent accidents and achieve the objectives of technical learning. According to [32] gestures can be used to fill a void or silence, which can be an additional function of nonverbal modality when verbal modality is not accessible. "SARA" said: "We must always be vigilant towards this discipline". Here arguments it seeks to hide his weaknesses to the taught material.

Regarding the use of illustrative gestures, it was observed that both our teachers use most illustrative and substitutional gestures that occupies second place in "SANA" and "SARA" respectively. This confirms the influence of expertise on the use of illustrative gestures. In this context, [15] highlighted the importance of this type of gesture in the transmission of knowledge. Thus, expert uses the illustrative type "partial demonstration" more than the novices. The partial demonstration is only one stage of construction needed in the establishment of an internal model in the subject and this with reference to the teacher's words "SANA": As a former athlete specialist "I demonstrate all the gesture to shot put step by step to a better understanding and memorizing".

[4] showed that the ability of the student to interpret the gesture does not depend only on the quality of gestures produced by the teacher, but other variables such as the level of skill in the activity, its theoretical and practical knowledge of the activity. Thus, with a higher level of skill, pupils interpret with pertinence and competence the teacher's gestures.

Concerning representational gesture of the learner evokes a mental pattern to reproduce gestures. This category gestures occupies a prominent place for the expert in the transmission of content and knowledge. While the polyvalent didn't use subcategories "evocation type of action" and "state evocation" belonging to gestures" representational". In this context, [33] explains that when a subject observes a model, it stores in memory the visual image of what he sees and then copy this model to produce a motor response. In this sense, [6] added that this type of action is either by a transposition when a body part is used to represent the action of another body part or by analogy melted on similarity reports meaning established by the imagination between different gestures. "SANA" says in the post session interview: "Mastery of different technical phases of the global movement is the key point that plays an important role in the success of the shot put and this is done from the images that I give students to memorize or to make a mental pattern". 
Our results showed a frequent use of this category by the expert. Indeed, the expert uses its in practical memories (athletics specialty for twelve years), to extract an action and schematically virtual in order to help the student to make the representation of a complete action or element of this action in his mind. In this context, [34] found that experienced teachers with a high level of expertise specialty in sports have a basic knowledge extended and articulated.

However, the polyvalent use rarely representational gestures in comparison with the expert. A possible explanation is that polyvalent has little practical experience (specialty is gymnastic).

Moreover, gestures of manipulation (correction) are most frequently used by the polyvalent in order to correct and help. She says after the post session interview "students are not too motivated for the specificity of the subject taught". One can imagine that a non-specialist teacher teaches without much difficulty to make gestures but nothing says that he will use them appropriately to promote its learning. For an expert this type of action and less frequent and occupies last place. In this sense, [35] indicates that the manipulation provides the desired posture without however being asked the question of what to do to get there.

Another possible explanation relates to the specificity of the subject taught. Indeed, the expert mastery teaching of shot put which explains the choice of representational gestures rather than others. [1] believe his side that the subject constructs a representation of the observed pattern in the encoding visual information, an image or words and for the gain of working time. It exposes us his approach: "I produce a mental pattern in students concerning the action to execute and stores it in its memory to retrieve it if necessary". Hence the potent place of this category in the act of transmitting content. Moreover, it makes use of partial demonstration to prevent tampering and to motivate students about the specificity of the discipline.

Concerning didactic functionality, definition in teaching ranks first in both teachers (expert and polyvalent). Concerning the regulation, it is higher in the expert in comparison with the polyvalent. In this sense, the nature of the discipline requires human and material organization to ensure both the safety of students and their apprenticeship. In fact, the teaching style used by the two teachers may partly explain the high percentage of using (start time, tempo, indicating place ...). According to SANA said "I prefer the style of command, I give orders and follows and implements learning; pedagogy command for the simple reason that it makes my job as a teacher to manage my classroom and again to ensure the safety, style requires a lot of correction to the level of execution."

For regulation, it ranks in second place for both teachers. Indeed, [27] argues that the regulatory process seeks to manage uncertainty among the student and helps overcome challenges and acquire new knowledge. This requires a good theoretical and practical knowledge of teaching activity [36]. Regulation is often presented as professionalizing. It is more effective and efficient among experts. Thus, the results obtained in this study demonstrate that expert regulate more than the polyvalent. 
Moreover, [37] showed that students are struggling to remember, to memorize vocabulary and properties. Hence, the importance of regulation according to SANA "All teaching proposing to fight against school failure must offer students learning situations taking into account the difficulty of discipline". Regarding the devolution function is higher in the expert. These results are in accordance with those of [14]. Moreover, [13] showed that, devolution is the commitment of students, guided by the teacher. This is to give meaning to knowledge, build relationships between knowledge.

However, the institutionalization function keeps the same rank independently on the teachers' expertise. Different teaching techniques are at work, some have the function of ensuring the progression of instructional time (chronogenesis technical), others play on the division of tasks and responsibilities (topogenesis technical) Finally, other (mesogenesis technical) fall within "the progressive development of an environment in which certain dimensions were set in the early moments of the lesson".

Our results showed that both teachers use Topogenesis gestures. Likewise, both teachers use in chronogenesis gestuality in the second place. [8] and [35] showed that "chronogenesis" in the most used in apprenticeship situations. However, the use of mesogenesis gestures is in last place. These results disagree with those of [8] that showed a superiority of this technique in the teaching of gymnastics.

\section{Conclusion}

The teaching gestures in the teaching of shot put depend on the teacher's expertise. However, more professional experience the teacher expands, more differences diminish due to the expertise.

\section{Limit of the Study}

This study has some limits. First, this is a case study; we regret not to work on a larger sample. Second, to investigate the effect level of expertise on the didactic functionality of the teaching gestures in the teaching who teach different physical activities and with different sex.

\section{References}

[1] Durand, M. and Rief, J. (1993) Planning and Decision among Teachers. Results from Studies in Physical Education, Analysis and Perspectives. French Revue of Pedagogy, 103, 81-07.

[2] Hall, E.T. (1978) Hidden Dimension. Seuil, Paris.

[3] Pieron, M. (1992) Pedagogy of Physical and Sport Activities. Review EPS, Paris. (In French)

[4] Mahut, B. (2003) Semiotic Approach Didactic Interactions; Gesture and Verb in a Situation of Physical Education and Sports. PhD Thesis, University of Franche Conte.

[5] Marsenach, J. and Mérand, R. (1987) Formative Assessment in PE in Colleges. Research Report, NPRI, Paris.

[6] Quintillan, G. (1992) Sports and Nonverbal Communication Teaching. PhD Thesis, University Paris V René Descartes. (Unpublished) 
[7] Vigarello, G. and Vivés, J. (1989) Gestures of the Coach and Technical Body. EPS Review, 216, 12-18.

[8] Kammoun, M. and Amade-Escot, C. (2007) Didactic Features of the Gestures of the Teacher of EPS: Comparative Analysis According Gymnastics Expertise. In: Carlier, G., Bouthier, D. and Bui-Xuân (Dir), Intervention in Physical Education and Sport, UCL, University Press of Louvain.

[9] Amade-Escot, C. (2000) The Use of Teaching Theories, Issues Raised by the Study of Didactic Contract. Physical Education. In: The Didactic Engineering, Uses and Misuses of Theories of Teaching, De Boeck, Brussels.

[10] Cizeron, M. and Gal-Petitfaux, N. (2003) Knowledge of Action and Justification of Knowledge in Teaching Situation: The Case of Gymnastics. French Review of Pedagogy, 143, 91-100. https:/doi.org/10.3406/rfp.2003.2956

[11] Cizeron, M. and Gal-Petitfaux, N. (2005) Knowing Gymnastics and Teach Namely PTA: The Nature of Pedagogical Content Knowledge and Its Relationship to Classroom Instruction. Science and Traction, 55, 9-38.

[12] Rovegno, I., Chen, W. and Todorovich, J. (2003) Accomplished Teachers' Pedagogical Content Knowledge of Teaching Dribbling to Third Grade Children. Journal of Teaching in Physical Education, 22, 426-449. https:/doi.org/10.1123/itpe.22.4.426

[13] Assude, T., Mercier, A. and Sensevy, G. (2007) The Didactic Action of the Teacher in Dynamic Environments. Research in Mathematics Education, 27, 221-252.

[14] Touboul, A., Carnus, A. and Terrisse, A. (2008) The Weight of the Expertise and Experience in Teaching Practices in Physical Education and Sport Contrasts Case Study Savate French Boxing. Science in Freedom. http://www.sciencelib.fr/index.php

[15] Kohler, M. (1998) The Partial Demonstration of EPS Teachers in Gymnastics: A Body Technique for Better Representation of Gesture. Dossier EPS, No. 39.

[16] Brossais, E. and Terrisse, A. (2009) The Weight of the Sports Institution in the Analysis of a Beginner-Expert in Judo Teacher. In: Carnus, M.-F. and Terrisse, A., Eds., Clinical Teaching of EPS: The Challenges of Knowledge? Oxford University Press, Brussels, 115-133.

[17] Leutenegger, F. (2003) Study of Educational Interactions in Math Class: A Methodological Prototype. Psychology Bulletin, 56, 559-571.

[18] Brousseau, G. (1978) Observation of Educational Activities. French Review of Education, 130-139.

[19] Amade-Escot, C. and Marsenach, J. (1995) Didactics of Physical Education and Sports. Theoretical Issues and Methodologies, INRP.

[20] Schubauer-Leoni, M.L. and Leutenegger, F. (2002) Explain and Understand in a Clinical Approach/Experimental Ordinary Teaching. In: Leutenegger, F. and Saada-Robert, M., Eds., Explain and Understand the Educational Sciences, De Boeck, Educational Reasons, Brussels, 227-251.

[21] Huberman, M. and Miles, M.B. (1991) Qualitative Data Analysis: Story Collection Methods. Oxford University Press, Brussels.

[22] Cosinier, J. (1982) Communications and Sign Languages. The Ways of the Language, Verbal, Gestural and Animal. Dunod, Paris, 255-304.

[23] Sensevy, G. (2001) Action Theory and Teacher Action. In: Baudouin, J.M. and Friedrich, J., Eds., Theories of Action and Education, De Boeck, Bruxelles, 203-224.

[24] Sensevy, G., Mercier, A. and Schubauer, L. (2000) Towards a Model of the Didactic Action of the Teacher about 20. In the Race for Research in Mathematics Education (20/3). The 
Savage Mind, Grenoble.

[25] Brousseau, G., Balacheff, N., Cooper, M. and Sutherlan, R. (1998) Theory of Didactic Situations: Teaching Mathematics, 1970-1990.

[26] Chevallard, Y. (1991) Basic Concepts of Didactics: Perspectives Provided by an Anthropological Approach. In: Douady, R. and Mercier, A., Eds., Research in Didactique of Mathematics, Mathematical and Computer Publications, Rennes, 160-163.

[27] Schubauer-Leoni, M.L. (2008) The Construction of the Reference in the Joint Action Teacher-Student. In: Wallian, N., Poggi, M.P. and Musard, M., Eds., Co-Construct Knowledge: The Art of Intervention by APSA, PUFC, Besançon, 67-86.

[28] Brousseau, G. (1986) Foundation and Method of the Mathematics Education Research in Mathematics Education.

[29] Schubauer-Leoni, M.L. (1996) Research Didactic Contract for Struggling Students in Math. Beyond Teaching, Teaching. De Boeck University, Brussels, 159-189.

[30] Verscheure, I. (2005) Dynamic Differential Didactic Interaction and Co-Construction of Gender Difference in Physical Education and Sportive: The Case of the Attack in Volleyball in Agricultural Schools. Doctoral Dissertation, III Paul Sabatier University, Toulouse, 3.

[31] Verscheure, I. and Amade-Escot, C. (2007) The Gendered Construction of Physical Education Content as the Result of the Differentiated Didactic Contract. Physical Education and Sport Pedagogy, 12, 245-272. https:/doi.org/10.1080/17408980701610185

[32] Baider, F., Roman, A. and Embleton, S. (1998) Verbal Metaphors and Nonverbal Metaphorics: What Can They Teach Us? The Linguistic Association of Canada and the United-States (LACUS) Forum, No. 24, 437-444.

[33] Cadopi, M. (1990) Memorisation and Reproduction Chaining in Women's Artistic Gymnastics. Laboratory Sport, Action, Optimization, Monpilier, 1.

[34] Durand, M. (1999) Efficiency, Expertise and Teaching Experience: Methodological and Theoretical Reflection.

[35] Garnier, A. (2003) The Report to Know the Teacher: Between Coercion and Autonomy. A Case Study at a College Gymnastics Teaching Cycle. PhD Thesis Teaching of Scientific and Technological Disciplines, III Paul Sabatier University, Toulouse.

[36] Tardif, M. and Lessard, C. (1999) The Teacher Daily Work. Experience, Human Interaction and Professional Dilemmas. Laval University Press, Brussels, De Boeck, Québec.

[37] Perrin-Glorian, M.J. (1999) Joint Problems of Theoretical Frameworks: The Example of the Concept of Environment. Research in Mathematic Didactics, 19, 279-322. 
Submit or recommend next manuscript to OALib Journal and we will provide best service for you:

- Publication frequency: Monthly

- 9 subject areas of science, technology and medicine

- Fair and rigorous peer-review system

- Fast publication process

- Article promotion in various social networking sites (LinkedIn, Facebook, Twitter, etc.)

- Maximum dissemination of your research work

Submit Your Paper Online: Click Here to Submit

Or Contact service@oalib.com 